\title{
Elevated levels of circulating insulin-like growth factor-I, IGF- binding globulin-3 and testosterone predict hormone-dependent breast cancer in postmenopausal women: A case-control study
}

\author{
ZSUZSANNA KAHÁN ${ }^{1}$, JÁNOS GARDI ${ }^{2}$, TIBOR NYÁRI ${ }^{3}$, IMRE FÖLDESI ${ }^{4}$, ROZÁLIA HAJNAL-PAPP 5 , \\ KATALIN ORMÁNDI ${ }^{6,8}$, GYÖRGY LÁZÁR ${ }^{7}$, LÁSZLÓ THURZÓ ${ }^{1}$ and ANDREW V. SCHALLY ${ }^{9}$ \\ Departments of ${ }^{1}$ Oncotherapy, ${ }^{2}$ Endocrinology, ${ }^{3}$ Medical Informatics, ${ }^{4}$ Gynecology and Obstetrics, ${ }^{5}$ Pathology, \\ ${ }^{6}$ Radiology, ${ }^{7}$ Surgery, University of Szeged, 12 Korányi Street; ${ }^{8}$ International Medical Center, 8 Semmelweis Street, \\ Szeged, Hungary; ${ }^{9}$ Department of Veterans Affairs Medical Center, 1201 Northwest 16th Street, Miami, FL 33125, USA
}

Received November 30, 2005; Accepted January 16, 2006

\begin{abstract}
There is increasing evidence that different types of breast cancers are related to distinct risk factors. We analyzed the risk of breast cancer with respect to circulating insulin-like growth factor (IGF)-I, IGF-binding protein (IGFBP)-3, 17ß-estradiol, estrone, testosterone, androstenedione and sex hormone-binding globulin (SHBG), taking into consideration the characteristics of the tumors. Plasma hormone levels of 102 postmenopausal patients with breast cancer detected by mammography screening, and 102 matched controls were analyzed in relation to the histological type, the status of the estrogen receptor (ER), the progesterone receptor (PR) and the HER2 in the tumors. Significant positive associations were revealed between the IGF-I concentration and the overall risk of breast cancer $(\mathrm{OR}=3.1,95 \% \mathrm{CI}: 1.5-6.2)$, $\mathrm{ER}+\mathrm{PR}+$ breast cancer $(\mathrm{OR}=2.4,95 \% \mathrm{CI}: 1.1-5.4)$ and $\mathrm{ER}+\mathrm{PR}-$ breast cancer $(\mathrm{OR}=4.3,95 \% \mathrm{CI}: 1.2-14.3)$ when the highest and the lowest ranges of IGF-I were compared. Significant associations were also found between the highest and the lowest quartiles of testosterone, resulting in $\mathrm{OR}=4.1(95 \% \mathrm{CI}$ : 1.8-9.4) for the risks of breast cancer and $\mathrm{OR}=5.8(96 \% \mathrm{CI}$ : 2.1-16.2) of ER+PR+ breast cancer. A synergy was seen between IGF-I and testosterone levels. When both plasma IGF-I and testosterone were in the highest quartile ranges, an $\mathrm{OR}=26.4$ (95\% CI: $1.6-426.5, \mathrm{p}=0.021)$ was computed for breast cancer overall. No significant synergistic effects could be demonstrated with other parameters. There were significant, 2.5-fold (95\% CI: $1.2-5.6$ ), and 16-fold (95\% CI: $2.0-133.5$ ) increases in the overall risks of breast cancer and of ER+PRbreast cancer, respectively, when the highest and the lowest
\end{abstract}

Correspondence to: Dr Zsuzsanna Kahán, Department of Oncotherapy, University of Szeged, Korányi fasor 12, H-6720 Szeged, Hungary

E-mail: kahan@onko.szote.u-szeged.hu

Key words: breast cancer risk, breast cancer subtypes, estrogen receptor, HER2, progesterone receptor quartiles of IGFBP-3 were compared. No associations were found between any of the hormones and the risk of ER-PRtumors. The increased prevalence of ER+ breast cancers in patients with higher levels of IGF-I, IGFBP-3 or testosterone implicate these hormones in the etiology of hormonedependent breast cancer. Additional analyses specific for breast cancer subtypes may shed light on the value of hormone determinations for tailored chemoprevention.

\section{Introduction}

Human breast cancers display diverse genetic, histological and radiomorphological patterns, natural histories and responses to treatments. There is increasing evidence that different types of breast cancers are related to distinct risk factors $(1,2)$.

The experimental and epidemiological findings consistently demonstrate the relationship between high levels of circulating insulin-like growth factor (IGF)-I and the risk of breast cancer (3-5). Most epidemiological studies have revealed a significant association between IGF-I and the risk of breast cancer only in premenopausal women (6-12), but in some studies a high IGF-I concentration was a marker of the risk of breast cancer in postmenopausal women (13), or of a higher risk in both premenopause and postmenopause (14-18). The circulating IGF-I level has been proposed as a surrogate biomarker for the risk of breast cancer in premenopausal women (19), and for identifying those who may benefit from treatment with fenretinide, which acts, at least in part, by reducing the plasma IGF-I level (20). Moreover, tamoxifen which reduces the risk of the hormone-dependent breast cancer, was shown to reduce the level of circulating IGF-I (21). The inhibition of the growth of various experimental IGF-I-dependent cancers, including breast cancers, by the antagonistic analogs of growth-hormone releasing hormone is exerted in part by the inhibition of the secretion of $\mathrm{GH}$ and the resulting decrease in the levels of hepatic IGF-I (22).

Positive associations between the risk of breast cancer and the estrogen and androgen levels have been suggested in postmenopausal women (23-25). Synergistic effects of IGF-I and IGF-binding protein (IGFBP)-3 with estrone and 
Table I. Characteristics (mean $\pm \mathrm{SE}$ ) of healthy controls and cases with breast tumors.

\begin{tabular}{lccccccc}
\hline Group & $\begin{array}{c}\text { Age } \\
\text { (years) }\end{array}$ & BMI & $\begin{array}{c}\text { Age at } \\
\text { menarche } \\
\text { (years) }\end{array}$ & $\begin{array}{c}\text { Age at } \\
\text { menopause } \\
\text { (years) }\end{array}$ & Parity & $\begin{array}{c}\text { Age at first } \\
\text { delivery } \\
\text { (years) }\end{array}$ & $\begin{array}{c}\text { Family history } \\
\text { of breast } \\
\text { cancer }(\%)\end{array}$ \\
\hline Controls $(\mathrm{n}=102)$ & $57.8 \pm 0.5$ & $28.6 \pm 0.5$ & $13.7 \pm 0.1$ & $48.0 \pm 0.5$ & $1.8 \pm 0.1$ & $21.8 \pm 0.7$ & $6(5.8)$ \\
Cases $(\mathrm{n}=102)$ & $58.1 \pm 0.6$ & $28.6 \pm 0.5$ & $13.5 \pm 0.2$ & $48.9 \pm 0.5$ & $1.7 \pm 0.1$ & $22.7 \pm 0.6$ & $13(12.7)$ \\
\hline
\end{tabular}

testosterone on the risk of breast cancer have been observed in premenopausal and postmenopausal Chinese women (9).

The incidence of estrogen receptor (ER)/progesterone receptor-positive $(\mathrm{PR}+)$ breast cancer may be halved, by hormonal manipulations which decrease the estrogenic effects in the breast but ER-negative (ER-) tumors are not prevented $(1,26)$. The histological type of the breast cancer and the expressions of ER, PR and HER2 are widely used in clinical practice as markers of hormone dependence. Some findings tend to indicate that certain hormones play a role in the development of specific breast cancers $(25,27,28)$. Positive associations were found between increased IGF-I and IGFBP-3 levels, and the risk of ER+ breast cancer in postmenopausal women in one case-cohort study, but when IGF-I and IGFBP-3 were mutually adjusted, a significant relation remained only with IGFBP-3 (27). Strong associations between the circulating sex hormone levels and the risk of ER+ breast cancer were demonstrated in postmenopausal women, in two case-control studies $(25,28)$. However, in a similar prospective case-control study, such associations were lacking, and the conclusion was drawn that the ER status of breast tumors is independent of the concentrations of endogenous estrogens (29). Estrogens and androgens were most strongly associated with in situ cancers in one study (25), but such associations were absent in another (30). Although epidemiological studies do not support the role of hormonal factors in the evolution of HER2+ breast cancers $(31,32)$, to our knowledge, the possibility of an association between circulating hormone levels and the HER2 status of breast cancers has not been examined in case-control studies.

Accordingly, we set out to analyze the risk of breast cancer in relation to IGF-I, IGFBP-3 and the sex hormones, taking into consideration the histology and the status of the hormone receptors and the HER 2 of the tumors. We report the findings of a case-control study in postmenopausal women.

\section{Materials and methods}

Study population. Between February 2002 and April 2004, women attending the national mammography-screening program were invited to provide blood samples for the measurement of hormones as prospective markers of the risk of breast cancer (within the Hungarian mammographyscreening program started in 2002, 45-65 year-old women are being invited for bilateral 2-view mammograms taken every 1-2 years). The study was approved by the Institutional Review Board of the University of Szeged. A total of 2027 women agreed to participate, and each gave her written informed consent. Some individuals $(<10)$ refused participation. Only women without diabetes, malignancy and who did not receive hormone replacement therapy (HRT) within the last 6 months were included in the study. Each participant underwent an in-person interview involving the use of a standard questionnaire. The information collected included demographic features, the menstrual and reproductive history, the duration of past hormone exposure, the individual medical history, and the family medical history. In addition, $10 \mathrm{ml}$ of blood was collected in sterile heparinized vacutainers, and immediately chilled. The plasma was separated and then divided into $1-\mathrm{ml}$ aliquots and stored at $-70^{\circ} \mathrm{C}$ until hormone determinations. Finally, the routine mammography-screening procedure including physical examination by a technician was carried out.

The menopausal status was established at the time of blood collection. A woman was defined as premenopausal if she had at least one natural menstrual cycle within the last 12 months, and as postmenopausal otherwise. Bilateral oophorectomy indicated a postmenopausal status. In the event of hysterectomy, the menopausal status was determined by the concentrations of plasma 17ß-estradiol, FSH and LH. Only postmenopausal women were included in the analysis. The cases comprised the early-breast cancer patients (mostly with non-palpable tumors) diagnosed within the mammographyscreening program. All patients were operated on at the Department of Surgery, University of Szeged. The control population consisted of the healthy women with no evidence of breast abnormalities. Two patients initially regarded as healthy controls developed breast cancer during the 26-month recruitment period of the study and were, therefore, included in the breast cancer group. Two other participants in the study population were diagnosed with non-breast malignancies after the recruitment, and consequently were excluded from the study. Information on the diagnosis, the stage of the disease and the tumor characteristics (histological type, and ER, PR and HER2 status determined by standard immunohistochemical analysis) was abstracted from the medical records. Samples with HER2 $2+$ or $3+$ staining were classified as HER2+, and the others as HER2-. For each case with breast cancer or a high-risk proliferative breast lesion, one control was matched (33) by age, menopausal status, body mass index (BMI), age at menarche, age at menopause, age at first fullterm delivery and parity, and the duration of past exposure to hormones.

Laboratory analyses. Radioimmunoassays (RIAs) or immunoradiometric assays (IRMAs) were utilized to determine IGF-I, 
Table II. Plasma hormone concentrations (mean \pm SE) by case or control status and the characteristics of the tumors.

\begin{tabular}{|c|c|c|c|c|c|c|c|}
\hline & $\begin{array}{l}\text { IGF-I } \\
(\mathrm{ng} / \mathrm{ml})\end{array}$ & $\begin{array}{c}\text { IGFBP-3 } \\
\left(\times 10^{2} \mathrm{ng} / \mathrm{ml}\right)\end{array}$ & $\begin{array}{l}\text { 17ß-estradiol } \\
(\mathrm{pg} / \mathrm{ml})\end{array}$ & $\begin{array}{l}\text { Estrone } \\
(\mathrm{pg} / \mathrm{ml})\end{array}$ & $\begin{array}{l}\text { Androstenedione } \\
(\mathrm{ng} / \mathrm{ml})\end{array}$ & $\begin{array}{l}\text { Testosterone } \\
(\mathrm{nmol} / \mathrm{l})\end{array}$ & $\begin{array}{c}\text { SHBG } \\
(\mathrm{nmol} / \mathrm{l})\end{array}$ \\
\hline Controls $(n=102)$ & $115.2 \pm 8.1$ & $50.2 \pm 0.9$ & $18.8 \pm 1.6$ & $40.85 \pm 7.7$ & $1.82 \pm 0.07$ & $1.82 \pm 0.10$ & $54.1 \pm 2.8$ \\
\hline Breast cancer $(n=102)$ & $157.7 \pm 8.2$ & $52.6 \pm 0.94$ & $17.0 \pm 1.1$ & $31.6 \pm 1.7$ & $1.73 \pm 0.07$ & $2.36 \pm 0.11$ & $52.9 \pm 2.5$ \\
\hline p-value & 0.0003 & 0.0775 & 0.3752 & 0.2428 & 0.39 & 0.0005 & 0.7681 \\
\hline$E R+P R+$ tumors $(n=64)$ & $149.4 \pm 9.9$ & $50.5 \pm 3.1$ & $18.4 \pm 1.5$ & $33.9 \pm 2.4$ & $1.8 \pm 0.1$ & $2.5 \pm 0.1$ & $51.1 \pm 3.4$ \\
\hline ER+PR- tumors $(n=23)$ & $165.3 \pm 18.7$ & $57.5 \pm 2.0$ & $13.7 \pm 0.8$ & $28.6 \pm 2.5$ & $1.5 \pm 0.1$ & $2.4 \pm 0.3$ & $54.6 \pm 3.9$ \\
\hline ER-PR- tumors $(n=10)$ & $169.2 \pm 28.3$ & $57.1 \pm 1.1$ & $12.7 \pm 1.3$ & $24.7 \pm 2.7$ & $1.36 \pm 0.1$ & $1.9 \pm 0.3$ & $54.7 \pm 7.6$ \\
\hline p-value & 0.62 & 0.0026 & 0.09 & 0.17 & 0.09 & 0.32 & 0.80 \\
\hline HER2 + tumors $(n=21)$ & $171.1 \pm 18.7$ & $56.56 \pm 2.1$ & $14.3 \pm 1.1$ & $27.9 \pm 2.7$ & $1.7 \pm 0.1$ & $2.4 \pm 0.2$ & $50.0 \pm 4.3$ \\
\hline HER2- tumors $(n=68)$ & $152.5 \pm 10.3$ & $51.21 \pm 1.1$ & $18.5 \pm 1.6$ & $33.5 \pm 2.3$ & $1.8 \pm 0.1$ & $2.5 \pm 0.1$ & $52.6 \pm 3.3$ \\
\hline p-value & 0.39 & 0.02 & 0.15 & 0.2 & 0.95 & 0.79 & 0.69 \\
\hline Invasive tumors $(\mathrm{n}=91)$ & $155.8 \pm 8.7$ & $52.3 \pm 1.0$ & $17.1 \pm 1.2$ & $32.7 \pm 1.8$ & $1.8 \pm 0.1$ & $2.4 \pm 0.1$ & $53.6 \pm 2.7$ \\
\hline Noninvasive tumors $(n=11)$ & $173.4 \pm 23.5$ & $54.7 \pm 2.1$ & $16.6 \pm 3.6$ & $22.64 \pm 3.6$ & $1.6 \pm 0.2$ & $1.9 \pm 0.3$ & $47.3 \pm 6.9$ \\
\hline p-value & 0.51 & 0.43 & 0.90 & 0.06 & 0.43 & 0.14 & 0.44 \\
\hline
\end{tabular}

IGFBP-3, androstenedione, 17ß-estradiol, estrone (Diagnostic Systems Laboratories, Webster, TX, USA), testosterone and sex hormone-binding globulin (SHBG) (Institute of Isotopes, Budapest, Hungary) concentrations. The hormones were measured in duplicates. The intra- and inter-assay coefficients of variation, for these methods, respectively, were: $8.6 \%$ and $6.9 \%$ for IGF-I, $4.9 \%$ and $4.2 \%$ for IGFBP-3, $7.0 \%$ and $12.6 \%$ for testosterone, $7.6 \%$ and $12.6 \%$ for SHBG, $5.4 \%$ and $8.3 \%$ for $17 ß$-estradiol, $5.3 \%$ and $6.5 \%$ for estrone, and $2.2 \%$ and $12.9 \%$ for androstenedione. To eliminate any measurement difference caused by batch-to-batch variation between the controls and the cases, we analyzed the matched control and case samples with the same batch.

Statistical analyses. The relationships between the plasma IGF-I and IGFBP-3 levels together with the concentrations of sex hormones and the risk of breast cancer were investigated. All statistical analyses were performed with Stata statistical software, version 8.0. The Chi-square test, the Student's t-test and one-way ANOVA were used. Matched data sets were analyzed by using the multiple logistic regression method. In the logistic regression model, the IGF-I ranges $<100.0$, $100.0-140.0,140.0-180.0$ and $>180.0 \mathrm{ng} / \mathrm{ml}$ were used to determine the risk of breast cancer. To calculate ORs in relation to other hormones, the plasma hormone levels were grouped using the method of Connor (34). The goodness-of-fit of significant logistic models was checked by using the Hosmer-Lemeshow method. A probability level of $\mathrm{p}<0.05$ was considered statistically significant.

\section{Results}

The baseline characteristics of the 102 breast cancer cases and the 102 controls were equally distributed (Table I). Pathological examination of the breast cancer cases after surgery revealed ductal cancer in situ in 11, and invasive cancer in
91 cases. Among the invasive cancers, there were 82 ductal, 7 lobular and 2 medullary cancers found. The status of the ER/PR and the HER2 of the tumors was known in 98 and 89 cases, respectively. Sixty-four tumors were $\mathrm{ER}+\mathrm{PR}+, 23$ were ER+PR-, and 10 were ER-PR- (Table II). One tumor was ER-PR+ but was excluded from the analysis during the stratification by the ER/PR status of the tumors. Twenty-one tumors were classified as HER2+, and 68 as HER2- (Table II).

The plasma IGF-I level was significantly higher $(\mathrm{p}=0.0003)$ for the breast cancer cases $(157.7 \pm 8.2 \mathrm{ng} / \mathrm{ml})$ than for the controls $(115.2 \pm 8.1 \mathrm{ng} / \mathrm{ml})$ in the overall population study (Table II). The molar IGF-I/IGFBP-3 ratio was significantly higher for the breast cancer cases than for the controls $(0.11 \pm 0.05$ vs. $0.08 \pm 0.05, p=0.0004)$. The levels of IGFBP-3, 17ß-estradiol, estrone, androstenedione and SHBG did not differ between the two groups. However, there was a significant difference between the breast cancer cases and the controls in mean plasma testosterone level $(2.36 \pm 0.11 \mathrm{vs}$. $1.82 \pm 0.10, \mathrm{p}=0.0005$ ) (Table II). The hormone levels in the cases of breast cancer stratified by the tumor ER/PR, HER2 or invasive vs. noninvasive status are also shown in Table II.

There were significant negative correlations between the BMI and IGF $(r=-0.24, p=0.014)$, and between the BMI and IGFBP-3 ( $\mathrm{r}=-0.21, \mathrm{p}=0.030)$ in the control group, but not in the breast cancer group. Significant correlations were found between IGF-I and IGFBP-3 ( $r=0.434, p<0.001$ and $\mathrm{r}=0.450, \mathrm{p}<0.001$ in the control and the breast cancer group, respectively), between IGF-I and SHBG ( $r=-0.186$, $\mathrm{p}=0.06$ and $\mathrm{r}=-0.205, \mathrm{p}=0.039$ in the controls and the breast cancer cases, respectively), and between the BMI and SHBG $(\mathrm{r}=-0.355, \mathrm{p}=0.0003$ and $\mathrm{r}=-0.305, \mathrm{p}=0.002$ in the controls and the breast cancer cases, respectively). No significant correlations were found between the plasma IGF-I and sex hormone levels, or between the age and any of the hormone levels, except for IGF-I. Likewise, no associations were found between the BMI and the levels of the sex hormones. 
Table III. Quartile ranges for plasma hormone levels based on the literature data (IGF-I) or the frequency distribution of the controls.

\begin{tabular}{lllll}
\hline IGF-I $(\mathrm{ng} / \mathrm{ml})$ & $<100.0$ & $100.0-140.0$ & $140.0-180.0$ & $>180.0$ \\
IGFBP-3 & $<43.9$ & $43.9-49.4$ & $49.4-54.7$ & $>54.7$ \\
$\left(\mathrm{x} 10^{2} \mathrm{ng} / \mathrm{ml}\right)$ & & & & \\
Estradiol $(\mathrm{pg} / \mathrm{ml})$ & $<11$ & $11.0-14.2$ & $14.2-17.9$ & $>17.9$ \\
Estrone $(\mathrm{pg} / \mathrm{ml})$ & $<19.5$ & $19.5-23.6$ & $23.6-35.0$ & $>35.0$ \\
Androstenedione & $<1.3$ & $1.3-1.8$ & $1.8-2.2$ & $>2.2$ \\
$(\mathrm{ng} / \mathrm{ml})$ & & & & \\
Testosterone & $<1.1$ & $1.1-1.7$ & $1.7-2.4$ & $>2.4$ \\
$(\mathrm{nmol} / \mathrm{l})$ & & & & \\
SHBG $(\mathrm{nmol} / \mathrm{l})$ & $<34.4$ & $34.4-48.5$ & $48.5-67.9$ & $>67.9$ \\
\hline
\end{tabular}

We detected decreased plasma IGF-I concentrations in multiparous women, but the difference did not attain the level of statistical significance.

The hormone levels were analyzed in a logistic regression model. To compute ORs, IGF-I measurements were categorized into the following ranges: $<100.0,100.0-140.0$, 140.0-180.0, and $>180.0 \mathrm{ng} / \mathrm{m}$; the other hormone levels were set into quartiles, using the frequency distribution of the controls (Table III). Significant positive associations were revealed between the IGF-I concentration and the overall risk of breast cancer $\left(\mathrm{OR}=3.1,95 \% \mathrm{CI}: 1.5-6.2, \mathrm{p}_{\text {trend }}=0.002\right)$, the risk of $\mathrm{ER}+\mathrm{PR}+$ breast cancer $(\mathrm{OR}=2.4,95 \% \mathrm{CI}: 1.1-5.4$, $\left.\mathrm{p}_{\text {trend }}=0.025\right)$ and the risk of $E R+P R$ - breast tumors $(\mathrm{OR}=4.3$, 95\% CI: $1.2-14.3, \mathrm{p}_{\text {trend }}=0.035$ ), when the highest and the lowest ranges of IGF-I were compared (Table IV). Such an association was lacking for the ER-PR- tumors. There were significant, 2.5 -fold (95\% CI: 1.2-5.6, $\mathrm{p}=0.036)$ and 16.3 -fold (95\% CI: $2.0-133.5, \mathrm{p}_{\text {trend }}=0.003$ ) increases in the risk of overall breast cancer, and in that of ER+PR- breast cancer, respectively, when the highest and the lowest quartiles of IGFBP-3 were compared (Table IV).

When the effect of testosterone was analyzed, significant associations were found as follows: $\mathrm{OR}=4.1$ (95\% CI: $1.8-9.4$, $\mathrm{p}=0.001)$ and $\mathrm{OR}=5.8$ (95\% CI: 2.1-16.2, $\mathrm{p}<0.001)$ for the risk of overall breast cancer and for that of $\mathrm{ER}+\mathrm{PR}+$ breast cancer, respectively (Table IV). No significant associations were revealed by the analysis on stratification by the HER2 status or the histological classification of the tumors (data not shown).

When the associations between the plasma hormone levels and the risk of invasive vs. noninvasive breast cancer were calculated, $\mathrm{OR}=4.8(95 \% \mathrm{CI}: 1.1-20.8, \mathrm{p}=0.040)$ and $\mathrm{OR}=2.9$ (95\% CI: 1.4-6.0, $\mathrm{p}=0.004)$, respectively were found, when the highest range of IGF-I was compared with the lowest. When testosterone was placed in the same model, $\mathrm{OR}=4.7$ (95\% CI: $2.0-11.3, \mathrm{p}=0.001$ ) was calculated for the risk of invasive breast cancer (Table IV), whereas no significant relationship was detected for in situ cancer.

The joint effects of the plasma levels of IGF-I, IGFBP-3 and testosterone were studied by including them in a multiple logistic regression model; for the risk of overall breast cancer, IGFBP-3 then lost its significant effect. However, IGFBP-3

Table IV. Overall risk of breast cancer according to quartile ranges of plasma hormone levels, and by the characteristics of the tumors.

\begin{tabular}{|c|c|c|c|c|c|c|c|c|c|c|c|c|c|c|}
\hline \multirow[b]{3}{*}{ IGF-I ng/ml } & \multirow{2}{*}{\multicolumn{2}{|c|}{1}} & \multicolumn{3}{|c|}{ Number of controls/cases } & \multicolumn{3}{|c|}{ OR/quartile ranges } & \multicolumn{3}{|c|}{$95 \% \mathrm{CI}$} & \multirow{2}{*}{$\begin{array}{l}\text { OR } \\
\text { for } \\
\text { trend }\end{array}$} & \multirow[t]{2}{*}{$95 \% \mathrm{CI}$} & \multirow{2}{*}{$\begin{array}{l}\mathrm{p} \text {-value } \\
\text { for } \\
\text { trend }\end{array}$} \\
\hline & & & & 2 & & & 3 & & & 4 & & & & \\
\hline & $50 / 28$ & 1.0 & $17 / 20$ & 2.1 & $0.95-4.65$ & $14 / 18$ & 2.3 & $0.99-5.30$ & $21 / 36$ & 3.1 & $1.50-6.22$ & 1.43 & $1.14-1.80$ & 0.002 \\
\hline $\mathrm{ER}+\mathrm{PR}+$ & $50 / 19$ & 1.0 & $17 / 13$ & 1.0 & $0.82-4.92$ & $14 / 13$ & 2.4 & $0.97-6.14$ & $21 / 19$ & 2.4 & $1.05-5.37$ & 1.34 & $1.03-1.74$ & 0.025 \\
\hline $\mathrm{ER}+\mathrm{PR}-$ & $50 / 5$ & 1.0 & $17 / 6$ & 3.5 & $0.95-13.0$ & $14 / 2$ & 1.4 & $0.24-8.16$ & $21 / 9$ & 4.3 & $1.2-14.3$ & 1.49 & $1.02-2.16$ & 0.035 \\
\hline Invasive & $50 / 25$ & 1.0 & $17 / 19$ & 2.2 & $0.99-5.03$ & $14 / 17$ & 2.4 & $1.03-5.70$ & $21 / 30$ & 2.9 & $1.37-5.96$ & 1.41 & $1.11-1.78$ & 0.004 \\
\hline Noninvasive & $50 / 3$ & 1.0 & $17 / 1$ & 0.98 & $0.09-10.06$ & $14 / 1$ & 1.2 & $0.11-12.35$ & $21 / 6$ & 4.8 & $1.1-20.8$ & 1.71 & $1.02-2.86$ & 0.040 \\
\hline IGFBP-3 ng/ml & $26 / 12$ & 1.0 & $23 / 20$ & 1.7 & $0.74-4.03$ & $27 / 21$ & 1.5 & $0.66-3.29$ & $26 / 49$ & 2.5 & $1.15-$ & 1.30 & $1.01-1.67$ & 0.036 \\
\hline $\mathrm{ER}+\mathrm{PR}-$ & $28 / 1$ & 1.0 & $21 / 5$ & 6.6 & $0.72-61.40$ & $29 / 2$ & 1.9 & $0.16-22.51$ & $24 / 14$ & 16.3 & $1.99-133.5$ & 2.11 & $1.27-3.49$ & 0.003 \\
\hline Estrone $\mathrm{pg} / \mathrm{ml}$ & $28 / 24$ & 1.0 & $23 / 13$ & 0.7 & $0.27-1.57$ & $26 / 32$ & 1.4 & $0.67-3.0$ & $25 / 33$ & 1.5 & $0.72-3.27$ & 1.21 & $0.95-1.54$ & 0.114 \\
\hline $\mathrm{ER}+\mathrm{PR}+$ & $28 / 14$ & 1.0 & $23 / 7$ & 0.6 & $0.21-1.76$ & $26 / 18$ & 1.4 & $0.57-3.33$ & $25 / 25$ & 2.0 & $0.86-4.66$ & 1.32 & $1.00-1.75$ & 0.045 \\
\hline Invasive & $28 / 18$ & 1.0 & $23 / 13$ & 0.9 & $0.36-2.16$ & $26 / 29$ & 1.7 & $0.78-3.83$ & $25 / 31$ & 1.9 & $0.87-4.26$ & 1.29 & $1.00-1.67$ & 0.044 \\
\hline $\begin{array}{l}\text { Testosterone } \\
\mathrm{nmol} / \mathrm{l}\end{array}$ & $26 / 12$ & 1.0 & $23 / 20$ & 1.9 & $0.75-4.67$ & $27 / 21$ & 1.7 & $0.69-4.10$ & $26 / 49$ & 4.1 & $1.77-9.39$ & 1.53 & $1.18-1.98$ & 0.001 \\
\hline $\mathrm{ER}+\mathrm{PR}+$ & $26 / 6$ & 1.0 & $23 / 10$ & 1.9 & $0.59-5.99$ & $27 / 13$ & 2.1 & $0.69-6.3$ & $26 / 35$ & 5.8 & $2.1-16.2$ & 1.78 & $1.30-2.42$ & $<10^{-3}$ \\
\hline c-erbB-2+ & $36 / 2$ & 1.0 & $41 / 2$ & 0.9 & $0.11-6.55$ & $43 / 5$ & 2.1 & $0.38-11.44$ & $63 / 12$ & 3.4 & $0.72-16.18$ & 1.64 & $1.02-2.63$ & 0.038 \\
\hline c-erbB-2- & $30 / 8$ & 1.0 & $31 / 12$ & 1.5 & $0.52-4.04$ & $34 / 14$ & 1.5 & $1.56-4.18$ & $41 / 34$ & 3.1 & $1.26-7.66$ & 1.45 & $1.10-1.91$ & 0.007 \\
\hline Invasive & $26 / 10$ & 1.0 & $23 / 18$ & 2.0 & $0.78-5.28$ & $27 / 16$ & 1.5 & $0.59-4.00$ & $26 / 47$ & 4.7 & $1.96-11.25$ & 1.59 & $1.22-2.08$ & 0.001 \\
\hline
\end{tabular}


Table V. OR and 95\% CI for postmenopausal breast cancers by the characteristics of the tumors.

\begin{tabular}{|c|c|c|c|}
\hline Breast cancer & OR & $95 \% \mathrm{CI}$ & $\mathrm{p}$ (test for trend) \\
\hline \multicolumn{4}{|l|}{ All } \\
\hline IGF-I & 1.37 & $1.06-1.76$ & 0.016 \\
\hline IGFBP-3 & 1.13 & $0.85-1.49$ & 0.395 \\
\hline Testosterone & 1.52 & $1.17-1.98$ & 0.001 \\
\hline \multicolumn{4}{|l|}{$\mathrm{ER}+\mathrm{PR}+$} \\
\hline IGF-I & 1.41 & $1.04-1.90$ & 0.025 \\
\hline IGFBP-3 & 0.96 & $0.69-1.34$ & 0.841 \\
\hline Testosterone & 1.82 & $1.33-2.51$ & $<0.001$ \\
\hline \multicolumn{4}{|l|}{$\mathrm{ER}+\mathrm{PR}-$} \\
\hline IGF-I & 1.18 & $0.77-1.80$ & 0.446 \\
\hline IGFBP-3 & 1.99 & $1.13-3.48$ & 0.016 \\
\hline Testosterone & 1.44 & $0.93-2.25$ & 0.101 \\
\hline \multicolumn{4}{|l|}{ ER-PR- } \\
\hline IGF-I & 1.28 & $0.72-2.29$ & 0.386 \\
\hline IGFBP-3 & 1.73 & $0.82-3.67$ & 0.148 \\
\hline Testosterone & 1.34 & $0.72-2.51$ & 0.350 \\
\hline \multicolumn{4}{|l|}{ HER2+ } \\
\hline IGF-I & 1.12 & $0.75-1.70$ & 0.563 \\
\hline IGFBP-3 & 1.45 & $0.87-2.40$ & 0.150 \\
\hline Testosterone & 1.63 & $1.01-2.62$ & 0.044 \\
\hline \multicolumn{4}{|l|}{ HER2- } \\
\hline IGF-I & 1.19 & $0.92-1.56$ & 0.176 \\
\hline IGFBP-3 & 0.98 & $0.73-1.32$ & 0.931 \\
\hline Testosterone & 1.44 & $1.09-1.90$ & 0.009 \\
\hline \multicolumn{4}{|l|}{ Invasive } \\
\hline IGF-I & 1.37 & $1.04-1.78$ & 0.020 \\
\hline IGFBP-3 & 1.08 & $0.81-1.44$ & 0.584 \\
\hline Testosterone & 1.59 & $1.21-2.09$ & 0.001 \\
\hline \multicolumn{4}{|l|}{ Noninvasive } \\
\hline IGF-I & 1.51 & $0.86-2.66$ & 0.147 \\
\hline IGFBP-3 & 1.57 & $0.77-3.18$ & 0.209 \\
\hline Testosterone & 1.20 & $0.65-2.21$ & 0.559 \\
\hline
\end{tabular}

remained significant for the ER+PR- subtype (Table V). Their joint effects were also analyzed at different combinations of their quartile ranges. When both plasma IGF-I and testosterone were in the highest quartile ranges, an $\mathrm{OR}=26.4$ (95\% CI: 1.6-426.5, $\mathrm{p}=0.021$ ) was computed for overall breast cancer. No significant synergistic effects could be demonstrated with other parameters.

Although there were no significant differences in the plasma estrone levels among cases and controls or the different subgroups of the breast cancer patients, a significant trend (OR 1.3) with increasing estrone levels was found for the risks of both $\mathrm{ER}+\mathrm{PR}+$ and invasive breast cancers (Table IV). Our data did not indicate a significant association between the risk of breast cancer in general, or of any of the specific subgroups, with elevated levels of circulating 17ß-estradiol, androtenedione or SHBG.

\section{Discussion}

We found a significant positive association between the plasma IGF-I and IGFBP-3 levels and the overall risk of breast cancer; likewise, a strong relationship was observed between these same parameters and the risk of ER+ breast cancers. Most of the earlier prospective studies (6-12) demonstrated a significant association between IGF-I and the risk of breast cancer exclusively in premenopausal women, or failed to detect such a relationship in postmenopausal women $(35,36)$. In other investigations, a high IGF-I concentration was a marker for the risk of breast cancer, irrespective of the menopausal status (14-18), and one investigation revealed a high breast cancer risk parallel to an elevated IGF-I concentration in postmenopausal Afro-American women (13). These studies (13-18), similarly to ours, were case-control studies, which may provide an explanation for the discrepancy and for our results. It has been proposed that, in case-control studies, the presence of the malignant tumor itself might affect the IGF-I and IGFBP-3 concentrations, thereby reflecting the tumor marker status rather than a true risk assessment (6). Singer et al investigated the IGF-I level in early breast cancer patients, but did not find any correlation between IGF-I and the tumor diameter (14). The IGF-I level is decreased in advanced cancer, probably because of the inanition $(4,37)$. On the other hand, IGF-I has been shown to enhance the survival, migration and growth of early melanoma cells, but not to exert such an effect on melanoma cells from advanced lesions (38). These concerns led us to study only early cancer cases, when the phenotype of the tumor probably reflects the role of the hormones better than in advanced stages. On the other hand, since the levels of circulating IGF-I and IGFBP-3 depend strongly on race, lifestyle and diet $(37,39)$, we cannot exclude the possibility that racial or nutritional factors also played a role in our findings.

The results on IGFBP-3 in the various studies are not in agreement, some show an increased risk $(16,27)$, others a decreased risk (12), and still others no difference in postmenopausal women $(10,15,35,36)$. Gronbaek et al analyzed the concentrations of the members of the IGF system in relation to the risk of breast cancer, taking into consideration the ER status of the tumors (27). In that case-cohort study, an increased risk of $\mathrm{ER}+$ breast cancer with elevation in the levels of IGFBP-3 and IGF-II in postmenopausal women was demonstrated. Although no association was observed between the risk of overall breast cancer and an elevated IGF-I level, IGF-I was significantly associated with the risk of ER+ breast cancer. This association disappeared after mutual adjustment for the concentrations of the other members of the IGF system (27). In support of these findings, we demonstrated significant associations between the level of IGF-I and the risk of both $\mathrm{ER}+\mathrm{PR}+$ and ER+PR- breast cancers. At the same time, an elevated IGFBP-3 level was strongly related to the occurrence of the ER+PR- subtype, but not to that of the ER+PR+ subtype. When the joint effect of IGF-I, IGFBP-3 and testosterone was analyzed, only IGFBP-3 remained significant for 
the ER+PR- subtype, suggesting an independent effect for IGFBP-3. It may be speculated that, as the ER+PR- and $\mathrm{ER}+\mathrm{PR}+$ breast cancers exhibit different responses to hormonal therapies (40), they represent different disease entities, thereby requiring different preventive interventions. To achieve this, specific risk-predictors are needed. Additional hormone receptor subtype-specific studies might support such a role for IGFBP-3.

We found a significantly higher plasma testosterone concentration in the breast cancer cases than in the controls, and a strong association between the risk of breast cancer and the plasma testosterone level, but there was no association with adrostenedione. Enhanced testosterone levels have been shown to increase the risk of breast cancer in most studies $(23,25,41,42)$, including case-control studies with a design similar to ours (9). Moreover, we detected a significant association between an elevated testosterone concentration and the risk of ER+PR+ breast cancers. This is consistent with the finding in a recent prospective study of a positive relation between an elevated testosterone level and the risk of ER+ breast cancer (25). However, we could not reveal an association between an elevated level of testosterone and the risk of ER+PR- breast cancers. This suggests that testosterone, a strong predictor for $\mathrm{ER}+\mathrm{PR}+$ breast cancers, is related to breast cancer risk differently than IGF-I and IGFBP-3.

Endogenous estrogens have been found to be significant breast cancer risk factors in prospective studies $(23-25,28)$, but the case-control studies displayed significant heterogeneity (24). Although our study did not demonstrate association between the levels of circulating estrogens and the risk of overall breast cancer, increased plasma estrone levels were related to the risk of $\mathrm{ER}+\mathrm{PR}+$ and invasive breast cancers. In the meta-analysis by The Endogenous Hormones and Breast Cancer Collaborative Group it was concluded that the postmenopausal risk of breast cancer was related to the levels of the sex hormones (23). In the same study, the relative risk also increased with increasing BMI, while the magnitude of the risk was substantially reduced by adjustment for the serum estrogen concentrations. In contrast, adjustment for the androgens had little effect on the excess risk (23). Our study revealed a significantly elevated testosterone level, but no significant difference in the levels of the estrogens as compared with those in the healthy controls. A possible explanation for this finding could be that the breast cancer patients and the controls were well-balanced for the BMI, which is a marker of postmenopausal estrogen production, while the circulating testosterone level is independent of the BMI. For a better understanding of our findings, we analyzed the estrogen levels in relation to some characteristics of the study individuals and the levels of other hormones determined. Nonetheless, no correlation was found between the levels of the estrogens and age, the BMI or other hormones.

In accordance with others $(23,43)$, we conclude that the SHBG level is inversely correlated with the BMI. The SHBG level did not display any association with the risk of breast cancer among postmenopausal women. This finding was consistent with the results of a similarly designed populationbased case-control study (9) and a prospective case-control study (25). Lukanova et al reported that the IGF-I concentration correlated positively with the concentrations of the androgens, but not with those of the estrogens (43). We did not observe correlations between the levels of IGF-I and any of the sex hormones. These results are consistent with the data of the case-control study of Yu et al (9).

To our knowledge, our study is the first in which hormone levels were examined in relation to the HER2 status of breast cancers. Our analysis suggests that the plasma IGF-I, IGFBP-3, 17ß-estradiol, estrone, androstenedione and SHBG concentrations are not related to the HER2 status of the tumors. The finding that testosterone is significantly associated with the risk of both HER2+ and HER2- tumors may be explained by the similar distribution of ER+ tumors within the HER2+ and HER2- subgroups. In a case-control study, risk factors for breast cancer such as an early age at menarche, a higher waisthip ratio, and a family history of breast or ovarian cancer were associated with an elevated risk of both HER2+ and HER2breast cancers (34). In another study, a large cohort of breast cancer patients were studied for the association of the HER2 status of the tumors and the endocrine history of the patients, including parity, the age at menarche and the age at menopause. HER2 + tumors occurred significantly more frequently than expected in women with a higher number of deliveries, later menarche and earlier menopause, when the protective endocrine factors were taken into account (31). The conclusion that most endocrine risk factors do not operate through an HER2 overexpression in breast carcinogenesis is consistent with our findings.

In the analysis by Missmer et al, both estrogens and androgens tended to be associated most strongly with in situ tumors (25). In contrast, no such association was found in a similar study (30). In our analysis, an elevated IGF-I level was the strongest indicator of the risk of in situ disease.

The only investigation of the joint effect of the members of the IGF system and the sex hormones was that by Yu et al (9). Their case-control study compared the plasma levels of IGFs and sex hormones in Chinese premenopausal and postmenopausal women matched for age and menopause. A synergistic effect on the risk of breast cancer was proposed for IGF-I or IGFBP-3 with estrone or testosterone among both premenopausal and postmenopausal women (9). We also found a strong synergy between IGF-I and testosterone on breast cancer risk, but no such effect was revealed for IGFBP-3.

Our case-control study pointed to positive relations between the IGF-I, IGFBP-3 and testosterone levels and the risks of both overall breast cancer and hormone-dependent breast cancer. The increased prevalence of ER+ breast cancers in patients with higher levels of IGF-I, IGFBP-3, testosterone and estrone implicate these factors in the evolution of hormone-dependent breast cancer. Additional breast cancer subtype-specific analyses may shed light on the value of hormone determinations for tailored chemoprevention.

\section{Acknowledgements}

This study was supported by grants from the Medical Research Council, Hungary, the Hungarian League Against Cancer, and Avon Cosmetics Hungary.

\section{References}

1. Cuzick J: Epidemiology of breast cancer - selected highlights. Breast 12: 405-411, 2003. 
2. Althuis MD, Fergenbaum JH, Garcia-Closas M, Brinton LA, Madigan MP and Sherman ME: Etiology of hormone receptordefined breast cancer: a systematic review of the literature. Cancer Epidemiol Biomarkers Prev 13: 1558-1568, 2004.

3. Pollak M: Insulin-like growth factor physiology and cancer risk. Eur J Cancer 36: 1224-1228, 2000

4. Khandwala HM, McCutcheon IE, Flyvbjerg A and Friend KE: The effects of insulin-like growth factors on tumorigenesis and neoplastic growth. End Rev 21: 215-244, 2000.

5. Wu Y, Cui K, Miyoshi K, Hennighausen L, Green JE, Setser J, LeRoith D and Yakar S: Reduced circulating insulin-like growth factor I levels delay the onset of chemically and genetically induced mammary tumors. Cancer Res 63: 4384-4388, 2003.

6. Renehan AG, Zwahlen M, Minder C, O'Dwyer ST, Shalet SM and Egger M: Insulin-like growth factor (IGF)-I, IGF-binding protein-3, and cancer risk: systematic review and meta-regression analysis. Lancet 363: 1346-1353, 2004.

7. Sugumar A, Liu Y-C, Qiang X, Koh Y-S and Matsuo K: Insulin-like growth factor (IGF)-I and IGF-binding protein 3 and the risk of premenopausal breast cancer: a meta-analysis of literature. Int J Cancer 11: 293-297, 2004.

8. Shi R, Yu H, McLarty J and Glass J: IGF-I and breast cancer: a metaanalysis. Int J Cancer 111: 418-423, 2004.

9. Yu H, Shu XO, Li BD, Dai Q, Gao YT, Jin F and Zheng W: Joint effect of insulin-like growth factors and sex steroids on breast cancer risk. Cancer Epidemiol Biomarkers Prev 12: 1067-1073, 2003.

10. Toniolo P, Bruning PF, Akhmedkhanov A, Bonfrer JM, Koenig KL, Lukanova A, Shore RE and Zeleniuch-Jacquotte A: Serum insulin-like growth factor-I and breast cancer. Int $\mathbf{J}$ Cancer 88: 828-832, 2000.

11. Hankinson SE, Willett WC, Colditz GA, Hunter DJ, Michaud DS, Deroo B, Rosner B, Speizer FE and Pollak M: Circulating concentrations of insulin-like growth factor-I and risk of breast cancer. Lancet 351: 1393-1396, 1998.

12. Krajcik RA, Borofsky ND, Massardo S and Orentreich N: Insulin-like growth factor I (IGF-I), IGF-binding proteins, and breast cancer. Cancer Epidemiol Biomarkers Prev 11: 1566-1573, 2002.

13. Agurs-Collins T, Adams-Campbell LL, Kim KS and Cullen KJ: Insulin-like growth factor- 1 and breast cancer risk in postmenopausal African-American women. Cancer Detect Prev 24 199-206, 2000.

14. Singer CF, Mogg M, Koestler W, Pacher M, Marton E, Kubista E and Schreiber M: Insulin-like growth factor (IGF)-I and IGF-II serum concentrations in patients with benign and malignant breast lesions: free IGF-II is correlated with breast size. Clin Cancer Res 10: 4003-4009, 2004

15. Li BD, Khosravi MJ, Berkel HJ, Diamandi A, Dayton MA, Smith $\mathrm{M}$ and $\mathrm{Yu} \mathrm{H}$ : Free insulin-like growth factor-I and breast cancer risk. Int J Cancer 91: 736-739, 2001.

16. Yu H, Jin F, Shu XO, Li BD, Dai Q, Cheng JR, Berkel HJ and Zheng W: Insulin-like growth factors and breast cancer risk in Chinese women. Cancer Epidemiol Biomarkers Prev 11: 705-712, 2002.

17. Peyrat JP, Bonneterre J, Hecquet B, Vennin P, Louchez MM, Fournier C, Lefebvre J and Demaille A: Plasma insulin-like growth factor-1 (IGF-1) concentrations in breast cancer. Eur J Cancer 29: 492-497, 1993

18. Johansson H, Baglietto L, Guerrieri-Gonzaga A, Bonanni B, Mariette F, Macis D, Serrano D, Sandri MT and Decensi A: Factors associated with circulating levels of insulin-like growth factor-I and insulin-like growth factor binding protein-3 in 740 women at risk for breast cancer. Breast Cancer Res Treat 88 : 63-73, 2004.

19. Decensi A, Bonanni B, Guerrieri-Gonzaga A, Torrisi R, Manetti L, Robertson C, De Palo G, Formelli F, Costa A and Veronesi U: Chemoprevention of breast cancer: the Italian experience. J Cell Biochem Suppl 34: 84-96, 2000.

20. Decensi A, Veronesi U, Miceli R, Johansson H, Mariani L, Camerini T, Di Mauro MG, Cavadini E, De Palo G, Costa A, Perloff M, Malone WF and Formelli F: Relationships between plasma insulin-like growth factor-I and insulin-like growth factor binding protein-3 and second breast cancer risk in a prevention trial of fenretinide. Clin Cancer Res 9: 4722-4729, 2003.

21. Bonanni B, Johansson H, Gandini S, Guerrieri-Gonzaga A, Torrisi R, Sandri MT, Cazzaniga M, Mora S, Robertson C, Lien EA and Decensi A: Effect of low dose tamoxifen on the insulin-like growth factor system in healthy women. Breast Cancer Res Treat 69: 21-27, 2001.
22. Schally AV and Varga JL: Antagonistic analogs of growth hormone-releasing hormone: new potential antitumor agents. Trends Endocrinol Metab 10: 383-391, 1999.

23. Endogenous Hormones and Breast Cancer Collaborative Group: Body mass index, serum sex hormones, and breast cancer risk in postmenopausal women. J Natl Cancer Inst 95: 1218-1226, 2003.

24. Thomas HV, Reeves GK and Key TJ: Endogenous estrogen and postmenopausal breast cancer: a quantitative review. Cancer Causes Control 8: 922-928, 1997.

25. Missmer SA, Eliassen AH, Barbieri RL and Hankinson SE: Endogenous estrogen, androgen, and progesterone concentrations and breast cancer risk among postmenopausal women. J Natl Cancer Inst 96: 1856-1865, 2004.

26. Cuzick J, Powles T, Veronesi U, Forbes J, Edwards R, Ashley S and Boyle P: Overview of the main outcomes in breast-cancer prevention trials. Lancet 361: 296-300, 2003.

27. Gronbaek H, Flyvbjerg A, Mellemkjaer L, Tjonneland A, Christensen J, Sorensen HT and Overvad K: Serum insulin-like growth factors, insulin-like growth factor binding proteins, and breast cancer risk in postmenopausal women. Cancer Epidemiol Biomarkers Prev 13: 1759-1764, 2004.

28. Miyoshi Y, Tanji Y, Taguchi T, Tamaki Y and Noguchi S: Association of serum estrone levels with estrogen receptorpositive breast cancer risk in postmenopausal Japanese women. Clin Cancer Res 9: 2229-2233, 2003.

29. Zeleniuch-Jacquotte A, Toniolo P, Levitz M, Levitz M, Shore RE, Koenig KL, Banerjee S, Strax P and Pasternack BS: Endogenous estrogens and risk of breast cancer by estrogen receptor status: a prospective study in postmenopausal women. Cancer Epidemiol Biomarkers Prev 4: 857-860, 1995.

30. Zeleniuch-Jacquotte A, Gu Y, Shore RE, Koenig KL, Arslan AA, Kato I, Rinaldi S, Kaaks R and Toniolo P: Postmenopausal levels of sex hormones and risk of breast cancer in situ: Results of a prospective study. Int J Cancer 114: 323-327, 2005.

31. Balsari A, Casalini P, Bufalino F and Ménard S: Role of hormonal risk factors in HER2-positive breast carcinomas. Br J Cancer 88: 1032-1034, 2003.

32. Huang WY, Newman B, Millikan RC, Conway K, Hulka BS, Schell MJ and Liu ET: Risk of breast cancer according to the status of HER-2/neu oncogene amplification. Cancer Epidemiol Biomarkers Prev 9: 65-71, 2000.

33. Woodward M: Epidemiology: Study Design and Data Analysis. Woodward M (ed). Chapman \& Hall/CRC, London, pp273-279, 1999.

34. Connor RJ: Grouping for testing trends in categorical data. J Am Statistical Assoc 67: 601-604, 1972.

35. Keinan-Boker L, Bueno De Mesquita HB, Kaaks R, van Gils CH, van Noord PA, Rinaldi S, Riboli E, Seidell JC, Grobbee DE and Peeters PH: Circulating levels of insulin-like growth factor, its binding proteins $-1,-2,-3$, C-peptide and risk of post-menopausal breast cancer. Int J Cancer 106: 90-95, 2003.

36. Schairer C, Hill D, Sturgeon SR, Fears T, Pollak M, Mies C, Ziegler RG, Hoover RN and Sherman ME: Serum concentrations of IGF-I, IGFBP-3 and c-peptide and risk of hyperplasia and cancer of the breast in postmenopausal women. Int J Cancer 108: 773-779, 2004.

37. Thissen J-P, Ketelslegers J-M and Underwood LE: Nutritional regulation of the insulin-like growth factors. End Rev 15: 80-101, 1994.

38. Satyamoorthy K, Li G, Vaidya B, Patel D and Herlyn M: Insulin-like growth factor-1 induces survival and growth of biologically early melanoma cells through both the mitogenactivated protein kinase and B-catenin pathways. Cancer Res 61: 7318-7324, 2000.

39. Boyd NF, Stone J, Vogt KN, Connelly BS, Martin LJ and Minkin S: Dietary fat and breast cancer risk revisited: a metaanalysis of the published literature. Br J Cancer 89: 1672-1685, 2003.

40. Winer EP, Hudis C, Burstein HJ, Wolff AC, Pritchard KI, Ingle JN, Chlebowski RT, Gelber R, Edge SB, Gralow J, Cobleigh MA, Mamounas EP, Goldstein LJ, Whelan TJ, Powles TJ, Bryant J, Perkins C, Perotti J, Braun S, Langer AS, Browman GP and Somerfield MR: American Society of Clinical Oncology Technology Assessment on the use of aromatase inhibitors as adjuvant therapy for postmenopausal women with hormone receptor-positive breast cancer: Status Report 2004. J Clin Oncol 23: 619-629, 2005. 
41. Dorgan JF, Longcope C, Stephensen HE, Falk RT, Miller R, Franz C, Kahle L, Campbell WS, Tangrea JA and Schatzkin A: Relation of prediagnostic serum estrogen and androgen levels to breast cancer risk. Cancer Epidemiol Biomarkers Prev 5: 533-539, 1996.

42. Berrino F, Muti P, Micheli A, Bolelli G, Krogh V, Sciajno R, Pisani P, Panico S and Secreto G: Serum sex hormone levels after menopause and subsequent breast cancer. J Natl Cancer Inst 88: 291-296, 1996.
43. Lukanova A, Lundin E, Zeleniuch-Jacquotte A, Muti P, Mure A, Rinaldi S, Dossus L, Micheli A, Arslan A, Lenner P, Shore RE, Krogh V, Koenig KL, Riboli E, Berrino F, Hallmans G, Stattin P, Toniolo P and Kaaks R: Body mass index, circulating levels of sex-steroid hormones, IGF-I and IGF-binding protein-3: a crosssectional study in healthy women. Eur J Endocrinol 150: 161-171, 2004. 